\title{
Propuestas para pensar procesos históricos de recepción radiofónica: biografías, memoria y trayectorias de familia
}

\author{
Héctor Gómez Vargas \\ Universidad lberoamericana-León
}

\section{Antecedentes. El punto de partida}

LAS REFLEXIONES que se presentan a continuación se proponen abordar la forma en que los individuos a la par que van desarrollando un proceso personal biográfico, desarrollan una "biografía radiofónica" (Gómez Vargas, 1994). Queremos asomarnos a ver cómo se van formando los públicos de una práctica cultural específica y cómo van conformando una identidad de radioescucha.

Todo esto se pretende ver desde las trayectorias familiares, que son los nichos donde se gestan las esferas primarias de la biografía individual (Galindo, 1987) y donde se gestan las microculturas primarias y básicas de todo individuo, y así encontrar las diferencias y similitudes, las ausencias y las presencias, las jerarquías e indiferencias de las distintas generaciones a una oferta cultural que también tiene un proceso histórico en desarrollo, una trayèctoria, y una presencia en la vida social, asimismo mutante en sus formas de sociabilidad y propuestas simbólicas, con la vida urbana y las relaciones sociales (Martín Barbero, 1992).

Los orígenes de estas reflexiones son los trabajos de investigación del proyecto La transformación de las ofertas culturales y sus públicos en México (genealogías, cartografías y prácticas culturales en el siglo $X X$ ) que el programa Cultura de la Universidad de Colima ha venido realizando para alimentar con información básica y de primera mano al Sistema Nacional de Información Cultural (SNIC) sobre los procesos y cambios culturales que se han dado en el país, y que la tendremos como

1 Este trabajo está apoyado por el Seminario de Estudios de la Cultura de la Dirección General de Culturas Populares del Consejo Nacional para la Cultura y las Artes. 
la investigación matriz. De este proyecto hemos desprendido un pequeño apartado de los diferentes campos culturales estudiados, y se concentra en el de los medios masivos y, de todos ellos, en la radio.

Debido a que la investigación se realiza en la ciudad de León, Guanajuato, algunas de las referencias o indicaciones se aluden a su situación concreta.

\section{Antecedentes. El reencuentro con la radio como objeto de estudio}

Partimos de un vacío, de una serie de "cajas negras" en el estudiode la comunicación (Fuentes Navarro, 1991; Murdock, 1990), la radio (Arredondo, 1988) y la cultura (García Canclini, 1992), pese a que en ellas se encuentran algunas de las avenidas para la comprensión de los cambios profundos (Martín Barbero, 1992; García Canclini, 1991) que viven las sociedades actuales.

El interés por estudiar la radio ha estado en función de las plataformas de análisis con las que se trabaja en su momento. Desde los inicios de los estudios de la comunicación en Estados Unidos, la radio cobró un destacado lugar en las agendas de las investigaciones ya que se le asumía como uno de los principales protagonistas en las tres áreas que menciona Paul Lazarsfeld (1982) como las primeras e inmediatas preocupaciones de los investigadores.

Conforme se desarrolla esta perspectiva teórica y aparece la televisión, la radio será relegada y dejará de incluirse en las agendas prioritarias de investigación. El traslado de esta perspectiva teórica a América Latina y la aparición de otros paradigmas emergentes, provocarán, por un lado, una indiferencia hacia la radio que se manifestará de variadas formas, desde la ignorancia y descalificación total hasta la agresión y desprecio por su carácter predominante y eminentemente comercial; por otro lado, también se verán posturas en las que a partir de un solo enfoque de estudio de la radio, se generaliza y se "supone" todo el fenómeno, y donde simplemente se dejan de trabajar aspectos sutiles y decisivos para manejarse a partir de estereotipos y supuestos que han detenido la búsqueda de métodos novedosos que puedan dar cuenta de la radio y sus diferentes dimensiones (Gómez Vargas, 1992).

$\mathrm{Al}$ ser seriamente cuestionados estos paradigmas y al empezar a trabajar desde las mediaciones, a la comunicación como cuestión de cultura y, por tanto, el reconocimiento al "re-ver el proceso entero de la comunicación desde su otro lado, 
el de la recepción, el de las resistencias que ahí tienen su lugar, el de la apropiación de los usos sociales" (Martín Barbero, 1987: 10), se recupera la importancia de la radio, pero de la radio comercial, la que oyen desde hace muchas décadas y más tiempo cada día las sociedades latinoamericanas, y que se convertirá en uno de los más notables esfuerzos para el estudio de las políticas, industrias y culturas populares de Latinoamérica (Martín Barbero, 1989).

No es sólo que las nuevas plataformas lo señalan y resaltan la importancia de estudiarlo, sino que en nuestras sociedades se habla y se dice que, desde que apareció, es el medio “ más popular”, es decir, el que está diariamente más cerca de la mayoría de los individuos a lo largo y ancho del país; el que se ha transformado junto con nuestras sociedades durante varias décadas; el que se adapta mejor no sólo a nuestra cultura, predominantemente oral, también a nuestras percepciones y sensibilidades, a nuestras memorias e identidades; uno de los medios de más fácil acceso y manipulación por parte de las mayorías y por un público eminentemente joven como todo indica que somos.

Cambiando las plataformas de análisis, se descubre a la radio como un medio amplio, intrincado, de múltiples ramificaciones y conexiones, sumamente complejo. Tiene una gran presencia entre nosotros a través de una ya larga vida, con una vitalidad que asombra a cualquiera, con una capacidad de transformarse y adaptarse no sólo a las incesantes cambios económicos, políticos y culturales de nuestros países, sino a cualquier situación de la vida diaria de cada sujeto social. La radio fue y es una de las maneras como se trabaja y ha re-trabajado la expresión y memoria oral en nuestras sociedades (González, 1994: 75), y es heredera, antecedente, cómplice y confidente de otras formas de manifestación de lo oral como el cine, el teatro, la televisión, el videoclip, etcétera (Quiroz, 1993/94). La radio es el cruce de múltiples mediaciones: no sólo es ella misma una mediación, sino que forma parte de una metamediación mayor al mediar lo ya mediado por otras instancias y, a la vez, ser mediada por ellas.

\section{Las preguntas, las intenciones}

Para poder realizar nuestro trabajo de investigación, nos interesa acercarnos a dar respuesta a una serie de preguntas ya expresadas en la investigación matriz. Entre ellas resaltamos, siempre en relación con la radio, las siguientes: 
¿Cómo se estableció y cómo ha cambiado la relación entre los públicos y las ofertas culturales localizadas dentro de distintas generaciones? ¿Perfiles de públicos?

¿Qué es lo que puede transmitir o heredar una familia a sus descendientes desde el punto de vista de la cultura?

$\square$ ¿Cuál es la estructura y la composición del equipamiento «cultural» en los hogares de México?

$\square$ ¿Cuáles son las valoraciones, las preferencias, los modos y hábitos de relación, uso y participación de los públicos con respecto a las ofertas culturales accesibles atrás descritas?

Todas estas interrogantes son básicas para entender cuestiones torales en los cambios culturales en el país a lo largo del presente siglo. Sin embargo, nuestro trabajo requiere de una serie de preguntas interrelacionadas, pero específicas, que nos permitan construir, en su momento, los rieles particulares que nos lleven a los objetivos que nos hemos trazado. Algunas de esas preguntas son:

A lo largo de la biografía individual, un actor social ¿cómo se va convirtiendo en público y cómo va desarrollándose su biografía radiofónica?

Las disposiciones familiares respecto a la radio, ise transmiten de una generación a otra? ¿cómo?

A partir de las trayectorias familiares, ¿podemos hablar de diferencias intra e intergeneracionales en las formas de ser público?

¿Quépesotienen las ofertas culturales radiofónicas establecidas en un contexto socio-histórico concreto para la gestación de cierto tipo de públicos radiofónicos?

Nos interesa realizar este trabajo en una ciudad del interior del país por varias razones:

a) La mayoría de los trabajos tienden a concentrarse en la ciudad de México, por lo que sólo se genera información de este lugar dejando muchas lagunas en lo que sucede en las diferentes regiones del país. De hecho, las transformaciones en las provincias son algunos de los cambios estructurales que hemos venido viviendo desde hace algunas décadas (Aguilar Camín, 1988). 
b) Además de que puede ayudar a profundizar y atender una preocupación y obsesión de los actuales estudios y teorías de la comunicación en América Latina, servirá para conocer la manera como las distintas provincias de México se han conformado y transformado a lo largo del presente siglo. En este caso lo hacemos a través de la manera como la radio y sus públicos se han relacionado y desarrollado.

c) En la mayoría de las provincias del país se han sentido cambios culturales de una manera radical. Esto se debe a algunos cambios estructurales internos de sus elementos, componentes, relaciones y contextos (Monsiváis, 1992) y al impacto y contacto de nuevos factores estructurales del país. La aparición de los medios masivos y la gestación de sus públicos en cualquier lugar, están íntimamente relacionados a las prácticas y dinámicas culturales, a los escenarios, a los actores e instituciones que históricamente se han dado cita, y a la manera como se han relacionado a lo largo del tiempo. Su presencia y actividad se enmarcan y contribuyen de manera notoria a esos cambios. El estudio en diferentes regiones o localidades cobra mayor relevancia porque son una especie de "laboratorio" que permite ver de una mejor manera todos estos procesos.

A través de métodos y técnicas cualitativas, para ver más a detalle nueștro objeto de estudio, se pretende trabajar con varias familias y, en cada una, con miembros de las distintas generaciones, con la ayuda de las metodologías y técnicas de la historia oral (Thompson, 1988) y de las historias de vida (Montero, 1990; Galindo, 1987a), ya que nos acercan al nivel de la historia de la vida cotidiana y de la memoria de un grupo social (Joutard, 1985: 253), para asomarnos a ver la manera como la gente fue asimilando las disposiciones y prácticas culturales de la radio y ser un público cultural.

\section{Oferta cultural radiofónica y campo cultural}

La historia está viva y vive en los sujetos y las relaciones sociales de una sociedad concreta (Galindo, 1986: 58). Observar a la radio es observar las formas de vida que se han ido, las que se conservan y las que se están formando. Por ella se asoman y cruzan gran parte de la vida cultural de la sociedad contemporánea, y con ello se puede ir encontrando el sentido, dirección e intensidad a las nuevas formas de 
vida social que se han ido gestando en una ciudad compleja, contradictoria, intrincada y en desarrollo, con un modo de vida cada vez más urbano, y toda la carga de dinámicas culturales que ello implica (Reguillo, 1992). En pocas palabras, es un pretexto y un texto idóneo para reconstruir y pensar algunas imágenes que han constituido y constituyen nuestra cultura, local y nacional.

Hablar de cultura, dirá José Joaquín Brunner, "exige referirse a representaciones colectivas, creencias profundas, estilos cognitivos, comunicación de símbolos, juegos de lenguaje, sedimentación de tradiciones, etc." (Brunner, 1987: 30). La cultura como los sentidos que habitan, gravitan y circulan en una sociedad concreta. Es decir, la cultura como una dimensión que está presente en todas las relaciones sociales de un grupo específico e histórico: además de que se materializa a través de discursos, objetos, acciones, actores, roles, tradiciones, espacios, genera relaciones y competencias de sentido. Al mismo tiempo que es socialmente, significa algo a alguien. Es una suma representaciones y orientaciones para el diario accionar social (Giménez, 1987). La cultura será aquella dimensión de la vida social que "le da espesor al presente y factibilidad al porvenir" (González, 1987: 9) ya que es el principio organizador de la experiencia cotidiana y el registro hecho piel de las memorias, las identidades y los imaginarios que han sedimentado en el accionar social de todo sujeto.

La cultura nos permite crear un puerto de entrada, una perspectiva de análisis para el estudio de la radio. Esta dimensión de análisis es entendida como “ el estudio de las formas simbólicas -es decir de las acciones, objetos y enunciados significativos de varios tipos- en relación con contextos y procesos, socialmente estructurados e históricamente específicos en los que, se producen, transmiten y reciben estas formas simbólicas" (Thompson, 1993: 149-150).

La actividad que la radio tendrá dentro de una sociedad como la ciudad de León desde sus inicios, ha de ser vista como una práctica, una modalidad de las distintas formas de apropiación, asimilación, transmisión y reelaboración de la vida cultural que ahí se han dado, y que tras un proceso de inserción y de especialización en su forma particular de acción la han constituido en una oferta cultural, es decir, la acción de distintas instituciones, actores, discursos y practicas sociales y culturales que con sus propias reglas, dispositivos, mecanismos, habilidades, competencias y límites no hacen otra cosa sino un trabajo profesional y especializado en "la construcción, preservación y promoción de diversos sentidos sociales de la vida y el mundo" (González, 1993: 3). Estas ofertas culturales remiten a contextos 
históricos más amplios, ya que se insertan dentro del accionar de un campo cultural, a la manera señalada por Pierre Bourdieu en su acepción de los campos (Bourdieu, 1971).

Es decir, cuando aparece la radio, se ubica dentro de un espacio social que históricamente se ha ido formando y por donde circulan ya, con procesos desiguales de especialización, formas y bienes simbólicos. En ese espacio o campo, busca su lugar particular y un saber comunicativo propio, una competencia particular, con la cual se conecta y se relaciona con un público que, también, va adquiriendo una nueva experiencia de vivir lo cultural (Mata, 1994).

\section{Radio, vida cotidiana y mediaciones}

Si queremos pensar la forma como se gestó un público radioescucha en un lugar concreto, y la manera como se gestan actualmente, desde la plataforma analítica de la cultura, esta nos invita a entender que en esta relación hay, mínimo, una situación doble: por un lado una forma específica de trabajar la radio históricamente conformada y delimitada, y, por el otro lado,unos sujetos social e históricamente ubicados.

Entender la forma como ha trabajado, y trabaja, es de suma importancia ya que serán los límites y posibilidades, los engranajes y mecanismos de acción y elección real, posible y deseable de sus receptores. Pensemos algunas de las mediaciones que la radio realizó una vez que se constituyó como oferta cultural:

a) Conforme llegó la radio a México y comenzó a trabajar, una serie de factores tanto económicos, políticos y sociales fueron conformando una estructura que caracterizará y le imprimirá a nivel nacional una forma de trabajo y de desarrollo.

Si bien desde temprana edad asumió los rasgos estructurales que hoy la caracterizan (SánchezRuizy Arredondo,1987) con un perfil eminentemente comercial, la desproporción de radiodifusoras comerciales y permisionadas, la concentración de la mayoría de las estaciones de radio en unos cuantos estados y en unas cuantas ciudades, su atención a una población eminentemente urbana, su agrupación en grupos radiofónicos, la música y la publicidad como la espina dorsal de su programación, podemos destacar que con todo y eso, al tener varias y variadas etapas (Romo, 1991), ha 
trabajado de diferente manera esos elementos, lo que nos hace suponer que los receptores, a lo largo del tiempo y por generaciones, lo han vivido de manera diferente. Se puede agregar que no sólo ha cambiado la forma de trabajar la radio: también la misma tecnología tanto para la producción como para el consumo que incide en factores como la forma de producir, integrándose a otras tecnologías (satélite, teléfono celular, fax, modem, etcétera), y la forma de conducir, tanto al integrar otras opciones de la industria cultural (reloj, disco compacto, cassette, televisión) y es llevado a $\boldsymbol{n}$ lugares mientras se hace $\boldsymbol{n}$ cosas, al tener variadas opciones de recurso tecnológico (portátil, radiograbadora, walkman, consola, modular, etcétera).

La manera como estos elementos se han dado y se han desarrollado en una ciudad como León, Guanajuato, hace que se constituya una oferta radiofónica con caracteristicas y peculiaridades muy singulares. En un lugar donde la radio permisionada tardó décadas en llegar, y cuando llegó por diversas causas, su presencia ha sido prácticamente fantasmal, se puede decir que un radiorreceptor local de una radio fuera de la comercial es impensable: no ha existido. A esto habría que añadir, que la forma como se ha producido radio, y sus transformaciones, ha recaído en una manera particular de generar modelos de identificación radiofónica, preñados de sus recursos, ritmos, niveles, capacidades, etapas y momentos: la radio local ha tenido permutaciones en su forma de producir y comercializar la radio, con lo cual géneros radiofónicos y musicales, recursos humanos y técnicos, y su capacidad de ser un espacio social al producir y transmitir desde y sobre lo que acontece en la vida diaria de la localidad unos se han ido, otros se han quedado, otros han regresado y otros han aparecido. Todo ello habla de las maneras y sus variaciones como han hecho y modelado, como lo hacen hoy día a día, competencias, capacidades y modalidades de relación con ella y, por tanto, de las rutas únicas y posibles de ser radioescucha leonés (Gómez Vargas, 1991).

b) Pero al prestar atención a lo que sucede en este lugar específico, vemos que toda forma simbólica aparece, se produce, circula y es recibida dentro de contextos históricos, previamente conformados yestructurados por la acción e interacción de diversas instituciones y actores sociales (Thompson, 1993). Dentro del accionar del campo cultural leonés ubicamos la presencia, 
actividad e interrelación, con desniveles y diferencias en su capacidad de legitimar y normar los sentidos y las prácticas sociales y culturales(González, 1987), de algunos de los principales subcampos. El siguiente esquema retoma a los principales subcampos y sugiere lo anterior:

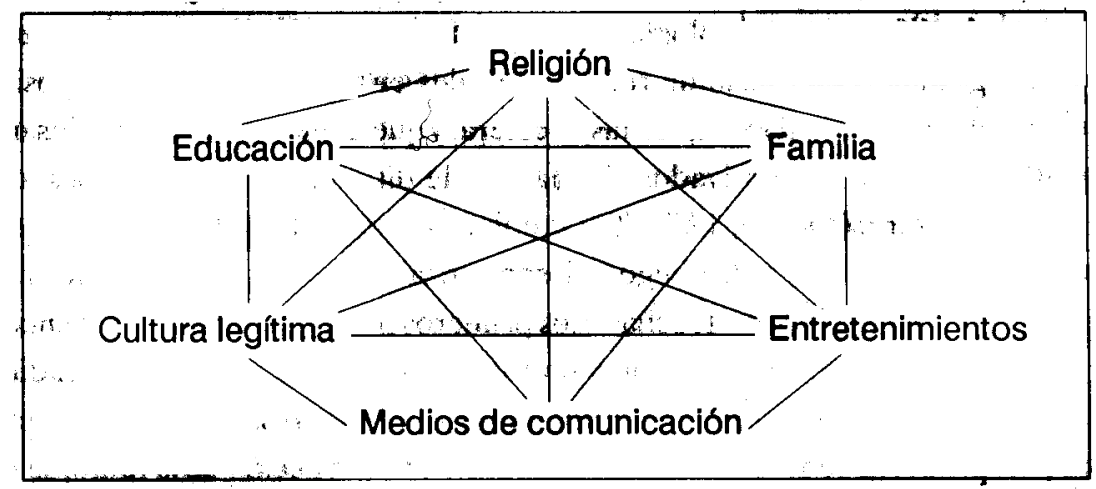

Cada uno de estos subcampos crearán y pondrán a trabajar una serie de instituciones que, también en forma diferenciada y desnivelada, no serán otra cosa sino espacios sociales, ubicados como espacios urbanos, y donde transmiten y asimilan las competencias particulares demandas de cada uno de ellos para formar a sus profesionales y a sus públicos. En cada uno de esos espacios sociales, se dará una acción simultánea en varios niveles para la transmisión/asimilación de las competencias necesarias para cada uno de ellos. Pensamos, mínimo en cuatro:

- Competencia del saber

- Competencia del nombrar

- Competencia del representar

- Competencia del actuar

Estos subcampos actuarán en red y en íntimas interdependencias inter e intra campales, y la radio como una forma simbólica y en su calidad de tecnología trabajará dos mecanismos: el primero, una filiación histórica por donde atraviesa el espesor cultural de una época y de un lugar, "a partir del cual se han definido y trazado territorios y saberes, oficios y géneros 
privilegiados, personajes, modas y formas de identidad reales o imaginarias, materias para hablar, técnicas y tendencias musicales, sistemas de producción y, en ese ámbito, un cuerpo de especialistas y profesionales de diversas industrias culturales (Piccini, 1987: 49). El segundo, una condensación histórica, es decir, el resultado de la trayectoria del trabajo social acumulado de diferentes tecnologías previas y formas simbólicas, por lo que se van gestando una serie de redes culturales en forma de relevos, oposiciones, complementaciones, luchas, etcétera, y que atañen tanto a espacios urbanos públicos como privados, formación de discursos, socializaciones, objetos, etcétera. (Piccini, 1987: 49).

Cuando la radio llegó a León, no había un espacio urbano, ni había locutores ni radioescuchas. Los primeros tiempos fueron para ir encontrando dónde se ubicaría, quién podría ser apto para trabajar en la radio y que pudiera ofrecer programas interesantes y atractivos. Por la naturaleza y las primeras concepciones sobre la naturaleza y la acción de la radio, se retomó a aquellos actores de otros campos que por sus competencias en el saber, en el nombrar, en el representar, en el actuar, pudieran ser sus primeros recursos humanos radiofónicos. Lo mismo en lo que se refiere a un programa atractivo: por un lado se acerca a aquellos espacios donde pudiera haber algo interesante en el campo de la diversión - tardeadas, bailes, ferias - la cultura legítima - conciertos, obras teatrales - la educación - conferencias - la vida social - discursos, días festivos, inauguraciones de comercios, celebraciones de aniversarios - pero también hacia ella se dirige lo que se hacía en otros lados, y substituye para algunos casos y en ciertas circunstancias, a lo que hicieron otros espacios en otros momentos: de las casas particulares a las arenas y auditorios, a la plaza de gallos, a la plaza de toros, a los teatros, a los cines, a la radio.

En este panorama, la radio será una oferta cultural en desarrollo y a través de la especialización de sus prácticas y saberes, tanto de los agentes productores como de los consumidores, los símbolos que los identifican y separan de los otros, las situaciones, los contextos, los valores y normas que van creando, y las formas y fuerzas de relación que entre ellos se daban, conformarán un nuevo mercado cultural (Bourdieu, 1990: 145).

A lo largo de su historia, la radio se va constituyendo en una oferta cultural, que una vez que ha ido conformando sus propias leyes, competencias y 
límites, "define dentro del vasto universo del discurso social común o doxa, un cierto conjunto de interpretaciones de segundo orden, jerarquizadas y sistematizadas en discursos, objetos, prácticas, clasificaciones, y rituales, etcétera".Estas ofertas culturales dentro de campos sociales como lafamilia, serán los límites posibles a partir de los cuales los receptores se van haciendo receptores, o "públicos culturales", o el "individuo consumidor de ese universo simbólico" (Brunner, 1992: 22) con lo cual no hará otra cosa sino "seleccionar, reconocer y apropiarse de ese universo", que permite la sedimentación histórica de lo que es posible elegir y gustar, pero también los límites de las estrategias y acciones de los radioescuchas.

c) El lugar donde la radio trabaja, se inscribe, se articula y entra en relación con el radiorreceptor será, desde siempre, la vida diaria, la vida cotidiana, la vida misma de los sujetos.

La radio se inserta a lo cotidiano a través de un doble mecanismo: se le escucha en un lugar, en un momento y mientras se hace algo. Es decir, se inserta y se integra a las situaciones cotidianas; pero, también, colabora a organizar las distintas situaciones cotidianas.

La radio será una mediación de las actividades cotidianas, imprimiéndole nuevas lógicas y dinámicas y nuevas formas de acción que repercuten en el accionar de lo privado y lo público, lo íntimo y lo social, lo cognitivo y lo afectivo, lo regular y lo extraordinario. Tras los objetos está la práctica social, los oficios, los saberes, las rutas de vida, los goces y sufrimientos, la diversión y el trabajo, lo público y lo privado: Porque como en la práctica de la lectura que no es una relación silenciosa y directa con el libro, sino que está acompañada de gestos, entonaciones, ritmos, ambientes y situaciones diversas y formas de lectura varias (Chartier, 1992), con todo objeto cultural (Giddens, 1990), tendrá una dimensión ampliada de sentidos donde se concentra y refleja el espíritu social (Elías, 1987: 164), a través de la reestructuración de las emociones, acciones, impulsos, relaciones, deseos, imaginarios, reglas y actitudes, que inciden en la vida de todos los actores sociales.

Cuando llega la radio, se convierte en un espacio que le permite a toda persona estar presente en todos lados y todos los acontecimientos importantes de la ciudad desde su hogar o el trabajo y hacer cosas que antes sólo en el exterior podía hacer, o hacer cosas nuevas o de una nueva manera: 
descansar, gozar, recordar, informarse, etcétera. Por ejemplo, con las primeras emisiones de radio, los acontecimientos sociales, culturales o políticos más importantes de la ciudad giraban alrededor de ella: la celebración del día de las madres en la plaza de toros, el discurso de toma de posesión del nuevo presidente municipal, la celebración de los juegos florales, la diversión diaria al tener en la ciudad a dónde ir con los teatro estudios, etcétera. Pero también, esos acontecimientos podían ser escuchados en la intimidad del mundo familiar; por aquellos que no podían asistir.

Lo anterior habla de mutaciones, algunas imperceptibles y muy lentas, en la vida cotidiana local a lo largo del tiempo y que todos sus actores sociales vivieron. Un ejemplo lo podemos encontrar en uno de los personajes importantes en la vida local de esos momentos, cuando recuerda cómo la vida en la ciudad, conforme pasa el tiempo, sufre afecciones sensibles en las tradiciones, las costumbres, los valores y las prácticas. De una de esas costumbres que ha perdido el aura de otros tiempos, y donde se asoma la radio, dirá:

Las posadas, que precedían al nacimiento también se despiden, ya no hay en ellas el paseo de las andas con la Virgen y San José pidiendo alojamiento de puerta en puerta alrededor del patio de la casa y cantando al son de la músicay de los pitos de aguinaldo; nise repartenal terminar modestas colaciones con cacahuates que cada quien "apara" en las manos "ahuecadas" y juntas para comerlas luego, o en canastitas de papel hechas en casa. Hoy si acaso se invita a una posada es para bailar al son del radio, que acabo con aquellos músicos que iban en tal ocasión con arpa, violín, flauta y "tololoche" o contrabajo a acompañar el canto de los villancicos al fin de cada misterio del rosario o el de la letanía al fin de este [subrayado nuestro] (Esquivel, 1992: 116).

\begin{abstract}
Ahora bien, en las tres mediaciones señaladas, su situación no será estática ya que, al ser en sí mismas trayectorias (González, 1994a: 335), conforme se desarrollan tanto el campo cultural, la tecnología radiofónica, la vida social, nuevas dinámicas y nuevas relaciones, nuevas formas de hacer radio se tendrán que implementar y otras morirán, que se reflejarán con las nuevas competencias, apreciaciones, acciones, equipamiento, emociones, ambientes y expectativas de los nuevos públicos radiofónicos. Cuando las ofertas culturales cambian en la forma de trabajar, cambian en la forma de sedimentar públicos, por lo que hablamos de que permanentemente se están creando públicos (Chartier, 1992: 108; Franco, 1995: 19).
\end{abstract}




\section{Biografías radiofónicas y trayectorias familiares}

El otro lado de la moneda: unos sujetos que todos los días prenden sus aparatitos y se ponen a escuchar la radio. Tanto el aparatito que no tiene nada de simple y el sujeto que lo prende son dos elementos sumamente complejos como para verlos a simple vista o dar cuenta de ellos en un plumazo.

La presencia de la radio en la vida de todo actor social se puede apreciar desde dos ángulos: a lo largo de su biografía y a lo largo de cada día.

La radio se inserta a la vida cotidiana a través de un proceso histórico de recepción, ya que la relación se ha dado a lo largo de los años y se actualiza día a día con variadas horas de escucha. Es la actualización de un hábito biográfico en uno cotidiano. La radio, entonces, es una compañera de muchas biografías y del recorrido de los itinerarios de muchos individuos.

Esto nos hace pensar que no basta entender el funcionamiento de la radio a partir de modelos programáticos donde cada estación transmite un género musical para segmentar al público, sino que al hacerlo generan lo que Cristina Mata (1988) llama "modelos de identificación y pautas comunicativas y culturales". Las estaciones no sólo presentan un contenido que es consumido porque agrada, sino que son "instituciones con historia" $y$, algunas, sobre todo las pocas que mantienen sus perfiles programáticos bien definidos, trabajan con ciertos géneros musicales que, también, poseen una "historia" y que no es otra cosa que, tanto la estación como cada género, han generado mecanismos y pautas de reconocimiento.

Entonces, tras de sí, todo sujeto tiene un pasado, un proceso de socialización y una trayectoria histórica. A la par que el sujeto se socializa y acarrea y es acarreado por los surcos históricos en los que es ubicadó y se ubica, se ha hecho radiorreceptor.

Introducirnos a la esfera de la historia familiar tiene un valor analítico fundamental por varias razones:

a) La familia como el estatuto que nos permite observar lo social, y desde la historia familiar el poder observar tanto los procesos de formación de trayectorias sociales a través de todos los individuos que conforman las redes familiares (Thompson, 1994); la sedimentación de micro culturas y sus prácticas, reglas, saberes, objetos, etc.; los procesos de transmisión y apropiación intergeneracionales de diferentes tipos de capitales; los contextos sociales donde viven y por donde atraviesan el tiempo histórico (internacio- 
nal, nacional, local), el familiar y el individual. La familia como los zurcos que muestran las diferentes formas de vivir, enfrentar y relacionarse con la vida social y cultural. Pensemos en lo dicho por Daniel e Isabel Bertaux:

Los niffos que crecen en el seno de esos microclimas tan diferenciados y con recursos tan desiguales, encarnan esas diferencias en sus maneras de ser, en sus relaciones con la escuela, con el dinero y con el porvenir (1994: 28).

b) Lafamilia como un espacio social que constituye un campo social, enmarcada e inserta en una red campal mayor, y que se materializa en forma de habitus, con su doble historicidad (la acumulada y las trayectorias posibles), como la matriz de prácticas sociales (percepción, valoración, actuación, estimación) y donde se ponen en juego los distintos capitales que se viven en familia (González, 1993a).

c) Mundo del individuo, la vida cotidiana tiene su punto de partida y de llegada en el ámbito familiar. Las rutinas, las trayectorias, las prácticas diarias van y vienen y son el punto de cruce, encuentro y desencuentro entre las nuevas y viejas formas de socialización, de consumir, de vivir y sentir lo público y lo privado (Piccini, 1993: 33). La familia como la primera comunidad de apropiación y de referencia de los mensajes radiofónicos (Orozco, 1991: 50)

Los receptores se hacen tales en un proceso biográfico, donde se van adquiriendo el capital cultural, las disposiciones para evaluar, percibir, negociar e incorporar los discursos y objetos mismos de la radio (Bourdieu, 1985), por lo que debemos hablar de la recepción como un proceso y del receptor como una biografía que se re-hace día a día. Es ese proceso el que nos interesa: las memorias suspendidas que quedan gravitando como anécdotas o recuerdos personales o grupales, aparentemente no tan importantes como los que marcan a la historia de la ciudad o del país, la familia, el individuo. Memorias de aquello que no se dice comúnmente, de las que uno no se detiene a pensar, pero que son tanto las que constituyen o han constituido gran parte de la vida y de los recuerdos de muchos sujetos, como donde se han puesto en funcionamiento muchas de las formas simbólicas de ese grupo social. Memorias, mundo de lo íntimo, terreno del instante que permanece en un perenne ahora en los territorios del tiempo que, como dice Octavio Paz es "la duración que no transcurre" (Paz, 1995: 7). 
Escuchar radio es más que un simple acto, un vínculo por el cual se actualiza la relación del medio con el receptor. Esta actualización implica una dinámica, un movimiento dirigido para mantener dicho vínculo: con su forma de vida, su concepción del mundo, sus sentimientos individuales y grupales, etcétera.

De larga presencia en el país, la radio se ha convertido en una institución social: es parte de su vida, de su cultura, de su memoria tanto en cada individuo o como grupo social. Esta práctica social de escuchar radio es parte integrante de ese mundo "heterogéneo" de lo cotidiano (Heller, 1984).

No todos los receptores son íguales (Orozco, 1990), sino que se hacen receptores de diferente manera de acuerdo con el lugar social que ocupan, las situaciones que viven día a día, sus pautas culturales y el proceso histórico de recepción que se ha dado a través de ciertas estaciones y las pautas comunicativas y culturales que han sedimentado, y que les permitirá la interiorización de disposiciones "incorporadas en familia y moduladas en las diferentes trayectorias de la vida de los individuos" (González, 1993a).

\section{Conclusiones. Pensar los procesos históricos de recepción}

Le doy vueltas al botón hasta llegar a la emisora más cercana, porque quiero provocar, en el sueño que se aproxima, imágenes más interesantes. En la emisora vecina una voz de mujer anuncia que el día será caluroso, pesado, con tormentas, y yo me alegro de que tengamosen Francia tantas emisoras de radioy de que en todasse diga, exactamente en el mismo momento, lo mismo acerca de lo mismo. (Milán Kundera, La inmortalidad).

Las reflexiones que se han presentado a lo largo del presente trabajo son tanto una serie de propuestas como una serie de apuestas. Propuestas porque en el campo académico de la comunicación en México la investigación ha encontrado a la radio como un objeto poco interesante y lo ha encerrado en un pequeño círculo de temas, alcances y metodologías posibles que no hacen otra cosa sino confirmar lo ya dicho: pese a ser uno de los medios más populares, tiene una relevancia social menor al de otros medios y en tres trazos se dice todo de este medio de comunicación. Nuestra propuesta es que no, la radio es un medio sumamente complejo, tanto como los tejidos sociales, y lo que necesitamos es enfocarlo y colocarlo en una 
posición tal que alrededor y a través de ella, veamos todo lo que ha sedimentado a lo largo de muchos años.

Quizá esto se vea mejor en una provincia, donde la mano de Dios sólo nos depositó, como el Mercurio de la modernidad, a dos o tres estaciones de radio y que por décadas fue $e l$ medio de comunicación con el cual y por donde las dinámicas sociales y culturales cobraron los nuevos cauces que ahora presentan.

Nuestra apuesta es que si lo ponemos en esas provincias y reconstruimos los procesos históricos de recepción que ahí se han dado, no sólo podemos generar información valiosa para la comprensión de las culturas locales, sino también la posibilidad de entrar al diálogo e interpelación con los actuales estudios de la recepción o, por qué no, fermentar nuevas rutas de investigación de la investigación para el futuro (Bruhn, 1993). Nuestra apuesta es mirar a las socializaciones pasadas para trabajar con las presentes y actuar en el futuro. Por lo mismo, estas reflexiones deben ser vistas como un proceso de reflexión todavía en ciernes.

\section{Referencias.bibliográficas}

Aguilar CAMín Héctor (1988): Después del milagro. México: Cal y Arena.

ARREDONDO Pablo (1988): "La radio como objeto de estudio en México". En Enrique E. SÁNCHEZ RUIZ (comp.) (1988): La investigación de la Comunicación en México. Logros, retos y perspectivas. México: Edicom.

BerTauX Daniel e Isabel BerTauX WiEME (1994): "El patrimonio y su linaje: transmisiones y movilidad social en cinco generaciones". Estudios sobre las Culturas Contemporáneas Vol. VI, Núm. 18. Colima: Universidad de Colima.

BOURDIEU Pierre (1971): “Campo intelectual y proyecto creador". En J. PouILLON et al: Problemas del estructuralismo. México: Siglo XXI (4a. Ed).

(1985): ¿Qué significa hablar? Economia de los intercambios simbólicos. Madrid: Akal, Col. Universitaria Núm. 81. 
(1990): "El mercado lingüístico". En Sociología y cultura. México: Grijalbo/CNCA.

BRUHN JENSEN Klaus (1993): "The past in the future: problems and potentials of historical reception studies". Joumal of Communication Vol, 43 (Autumn), International Communication Association.

BRUNNER José Joaquín (1987): “Notas sobre la modernidad y lo posmoderno en la cultura latinoamericana”. David y Goliat Año XVII, Núm. 52, Flacso.

(1992):América Latina: cultura y modernidad.México: Grijalbo/CNCA, Col. Claves de América Latina.

CHARTIER Roger (1992): El mundo como representación. Historia cultural: entre práctica y representación. Barcelona: Gedisa.

Elías Norbert (1987): El proceso de la civilización. Investigaciones sociogenéticas y psicogenéticas. México: Fondo de Cultura Económica.

ESQUIVEL Toribio (1992): Recordatorios públicos y privados. León 1864-1908. México: Universidad Iberoamericana/H. Ayuntamiento de León 19881994/Consejo para la Cultura de León.

FRANCo Jean (1995): “¿Dónde quedó la intelligentsia? El futuro incierto de la palabra impresa". La Jomada, La jornada semanal Núm. 291, 8 de enero.

FUENTES NAVARRo Raúl (1991): La comunidad desapercibida. Investigación e investigadores de la comunicación en México. Guadalajara: ITESO/Coneicc.

GALINDo Jesús (1986): "Historia y conciencia histórica del México contemporáneo: movimientos sociales y cultura política". Estudios sobre las Culturas Contemporáneas Vol:1, Núm. 1. Colima: Universidad de Colima. 
- (1987a): "Encuentro de subjetividades, objetividad descubierta. La entrevista como centro de trabajo etnográfico". Estudios sobre las Culturas Contemporáneas Vol. 1, Núm. 3. Colima: Universidad de Colima.

GaRcía CANClini Néstor (1991): "El consumo sirve para pensar". Diá-logos de la Comunicación Núm. 30 (Junio), Felafacs.

- (1992): "Los estudios sobre comunicación y consumo: el trabajo interdisciplinario en tiempos neoconservadores". Diá-logos de la Comunicación Núm. 32 (marzo), Felafacs.

GIDDENS Anthony (1990): "El estructụralismo, el post-estructuralismo y la producción de la cultura". En A. GIDDENS, A. et al. La teoría social hoy. México/CNCA/Alianza.

GiMÉNEZ Gilberto (1987): "La problemática de la cultura en ciencias sociales". En G. GIMÉNEZL La teoriay el análisis de la cultura.México: SEP/UdeG/Comecso.

GÓMEZ VARGAS Héctor (1991): "La radio en León: el guiño del ojo". Andanzas Núm. 3 (otoño). León: Universidad Iberoamericana.

(1992): "En búsqueda de la audiencia radiofónica". Comunicación y Sociedad Núms. 14-15 (enero-agosto). Guadalajara: Centro de Estudios de la Información y la Comunicación de la Universidad de Guadalajara.

(1994): "Usos sociales de la radio: que no pare la música". Estudios sobre las culturas contemporáneas Vol. VI, Núms. 16-17. Colima: Universidad de Colima.

GONZÁLEZJorge (1987): "Los frentes culturales. Culturas, mapas, poderes y luchas por las definiciones legítimas de los sentidos sociales de la vida". Estudios sobre las culturas contemporáneas. Vol. I, Núm. 3. Colima: Universidad de Colima. 
- (1993): "La transformación de las ofertas culturales y sus públicos en México (genealogías, cartografías y prácticas culturales en el siglo XX)". Tiempos Núm. 18. León: Archivo Histórico Municipal.

(1993a): "Navegar procelosos mares del placer". Estudios sobrelas Culturas Contemporáneas Vol. V, Núm. 15. Colima: Universidad de Colima.

- (1994): "La razón y el corazón en los muy platicados tiempos del cólera: oralidad, modernidad y medios (a tres caídas sin límites de tiempo)". En J. C. Lozano (ed.) Anuario de Investigación de la Comunicación Coneicc I. Guadalajara, México: Coneicc.

(1994a): Más (+) cultura (s). México: Consejo Nacional para la Cultura y las Artes, Colección Pensar la Cultura.

HeLler Agnes (1984): Historia y vida cotidiana. México: Grijalbo.

JOUTARD Philippe (1985): Esas voces que nos llegan del pasado. México: Fondo de Cultura Económica, Colección Popular Núm. 345.

LAZARSFELD Paul (1982): "Pronóstico para una investigación de las comunicaciones internacionales". En Miquel de Moragas (ed.) Sociología de la Comunicación de Masas (2a. ed). Barcelona: Gustavo Gili.

MARTÍN BARBERo Jesús (1987): De los medios a las mediaciones. Comunicación, cultura y hegemonía. México: Gustavo Gili.

(1989): "Panorama bibliográfico de la investigación latinoamericana en comunicación: 1985-1989". Telos Núm. 19. Fundesco.

(1991): "Recepción: uso de medios y consumo cultural". Diá-logos de la Comunicación Núm. 30 (junio). Felafacs.

_ـ (1992): "Pensar la sociedad desde la comunicación. Un lugar estratégico para el debate a la modernidad". Diá-logos de la Comunicación Núm. 32 (marzo). Felafacs. 
Mata Ma. Cristina (1988): "Radio y públicos populares". Diá-logos de la Comunicación Núm. 19. Felafacs.

- (1994): "Públicos, identidad y cultura. Aproximaciones conceptuales." Estudios sobre las culturas contemporáneas Vol. VI, Núms. 16-17, Colima: Universidad de Colima.

MoNSIVÁIS Carlos (1992): "De la cultura mexicana en vísperas del Tratado de Libre Comercio". En Gilberto GuEVARA NIEBLa y Néstor GARCía CANCLINI (coords.) La educación y la cultura ante el Tratado de Libre Comercio. México: Nueva Imagen/Fundación Nexos.

MONTERo Maritza (1990): "Memoria e ideología. Historias de vida: memoria individual y colectiva". Acta Sociológica Núm. 1 (enero-abril). México: Facultad de Ciencias Políticas y Sociales de la UNAM.

MURDOCK Graham (1990): "La investigación crítica y las audiencias activas". Estudios sobre las culturas contemporáneas Vol. IV, Núm. 10. Colima: Universidad de Colima.

Orozco Guillermo (1990): "El niño como televidente no nace, se hace". En Mercedes CHARLESyGuillermo OROZCO(comps.)Educación parala recepción. México: Trillas.

(1991): "Mapa para abordar las mediaciones en el proceso de recepción televisiva. Una aproximación metodológica". En Recepción televisiva. Tres aproximaciones y una razón para su estudio. México: Uia Sta. fe, Cuadernos de Comunicación y Prácticas Sociales Núm. 2.

PAZ Octavio (1995): “El instante y el calendario”. Vuelta Núm. 219 (febrero).

PICCINI Mabel (1987): "De políticas y poéticas: el orden de la comunicación". En M. PICCINI (ed.) La imagen del tejedor. México: Gustavo Gili/Felafacs. 
(1993): "La sociedad de los espectadores. Notas sobre algunas teorías de la recepción". Versión Núm. 3. México: Universidad Autónoma Metropolitana Xochimilco.

Quiroz Teresa (1993/94): "Los caminos de la radionovela a la telenovela en Perú". Renglones Núm. 27. Guadalajara: ITESO.

Reguillo Rossana (1992): "La ciudad es el campo: una contradicción llena de sentido". Comunicación y Sociedad Núms. 14-15. Guadalajara: Centro de Estudios de la Información y la Comunicación de la Universidad de Guadalajara.

RoMo Cristina (1991): Ondas, canales y mensajes. Guadalajara: ITESO.

SÁNCHEZ RuIZ Enrique y Pablo ARREDONDO (1987): Comunicación social, poder y democracia en México. Guadalajara: Universidad de Guadalajara.

THOMPSON John (1993). "La comunicación masiva y la cultura moderna. Contribución a una teoría crítica de la ideología”. En Ideología y cultura moderna. Teoría social en la era de la comunicación de masas. México: Universidad Autónoma Metropolitana Xochimilco.

Thompson Paul (1988): La voz del pasado. Historia oral. Valencia: España. (1994): "La familia como factor de movilidad social". Estudios sobre las culturas contemporáneas Vol. VI, Núm. 18. Colima: Universidad de Colima. 